\title{
EAl Endorsed Transactions

\section{Design and Development of a New Wideband CPW Fed Patch Antenna for Wireless Communication}

\author{
Purnima Sharma ${ }^{1, *}$ and P. P. Bhattacharya ${ }^{2}$ \\ ${ }^{1}$ School of Engineering and Technology, Mody University of Science \& Technology, Lakshmangarh, India \\ ${ }^{2}$ Asansol Engineering College, Vivekananda Sarani, Kanyapur, Asansol, West Bengal, India
}

\section{Abstract}

The present work shows a compact size coplanar waveguide (CPW) fed antenna for ultra-wideband (UWB) communication. The designed antenna has a dimension of $20 \times 20 \times 1.5 \mathrm{~mm}^{3}$. The proposed antenna design comprises of a slotted rectangular patch etched on an inexpensive FR4 substrate. The proposed antenna offers a good impedance matching over a frequency range of $5.7-8 \mathrm{GHz}$. The characteristic parameters such as return loss, VSWR, radiation pattern and input impedance are analyzed using HFSS 11.0. Designed antenna is fabricated and tested. This antenna is found to be appropriate for various IoT based applications.

Keywords: omnidirectional, return loss, ultra-wideband, wireless communication

Received on 13 November 2018, accepted on 08 January 2019, published on 28 January 2019

Copyright $\odot 2019$ Purnima Sharma et al., licensed to EAI. This is an open access article distributed under the terms of the Creative Commons Attribution licence (http://creativecommons.org/licenses/by/3.0/), which permits unlimited use, distribution and reproduction in any medium so long as the original work is properly cited.

doi: 10.4108/eai.31-10-2018.162734

*Corresponding author. Email:purnimasharma.1487@gmail.com

\section{Introduction}

The Federal Communications Commission (FCC) has defined ultra-wideband as any signal that occupies a frequency band between $3.1 \mathrm{GHz}$ to $10.6 \mathrm{GHz}$ [1]. UWB provides an efficient transmission with low cost in wireless communication systems [2]. While designing UWB antenna the main challenge is to maintain compactness, wide impedance bandwidth and stable radiation pattern [3]. Various UWB antennas have been reported in the literature.

In [4], a CPW fed scaled down size microstrip patch antenna is displayed for ultra-wideband wireless applications. This antenna possessed an inverted L-strip on the radiating patch to reduce monopole antenna's height. A good impedance-matching characteristic and consistent gain were achieved in the whole bandwidth of 2.6 to $13.04 \mathrm{GHz}$. A flexible dual-band antenna for applications such as WiMAX and X-band is presented in [5]. The basic bow-tie shape design has been replaced by fishtail shape. This antenna gives a bandwidth of around $7 \mathrm{GHz}$ in an upper frequency band. A CPW fed UWB compact antenna is discussed in [6]. A novel type of slot structure, radiating patch and co-ground structure has made this antenna small in size in comparison to various existing antennas. The hexagonally molded fractal geometry based microstrip antenna driven through CPW fed for various ultra-wideband wireless applications are presented in [7]. It has shown constant gain, good impedance matching and stable radiation pattern characteristics over a UWB frequency range. A novel compact-size structure of CPW-fed antenna with a wide bandwidth of 1.2 to $25 \mathrm{GHz}$ has been investigated in [8]. The antenna consists of a circular disc, a spiral split ring resonator and CPW fed along with two tapered transmission lines for improving broadband impedance matching in the required band. In [9], application of inkjet-printing on Molded Interconnect Devices technology for designing of ultra-wideband antennas is presented. This printed antenna shows an impedance 
matching over the whole ultra-bandwidth of $10 \mathrm{GHz}$. Peng et al. presented a novel design consisting of electromagnetic bandgap geometry on the CPW feedline [10]. It is shown that by using Electromagnetic band-gap (EBG) structure, band notched performance of the antenna can be controlled. To achieve wideband performance capacitive slits and the truncated ground plane is used by Alibakshi et al. [11]. The antenna produces an impedance bandwidth of $5.25 \mathrm{GHz}$ and 5.35 $\mathrm{dBi}$ gain. A UWB antenna with triple notched bands covering various wireless applications is reported by Sharma et al. [12]. The bandwidth achieved is $10.74 \mathrm{GHz}$ with an omnidirectional radiation pattern.

As planar and compact antennas are used in mobile devices, there is a need of planar antennas with wideband responses. In this paper a CPW fed planar antenna is designed for use in IoT based wireless devices. The CPW antennas are promising candidates for microwave and millimeter wave application due to their unique features such as reduced dispersion, low radiation losses, wide bandwidth and low cost etc.

The construction of the proposed antenna is defined in Section 2. In Section 3, a parametric study to find out the optimized dimensions of the proposed design is presented. Fabrication and measurement results are included in Section 4. Finally, conclusion and future scope of work are discussed in Section 5.

\section{Design of Proposed Antenna}

The antenna comprises of a symmetrical slotted CPW fed rectangular patch over an FR4 substrate as shown in Fig. 1. The antenna dimensions are chosen to meet the requirement of compactness. As the bandwidth of patch antenna is generally narrow, slots have been created to enhance the bandwidth. Three slots have been created in the rectangular patch of size $11 \times 8 \mathrm{~mm}^{2}$. FR4 substrate is used as it is easily available and easy for prototyping in laboratories. CPW fed line width is $3 \mathrm{~mm}$ to achieve proper impedance matching. The designed antenna is compact in size as compared to antennas presented in [4, $5]$.

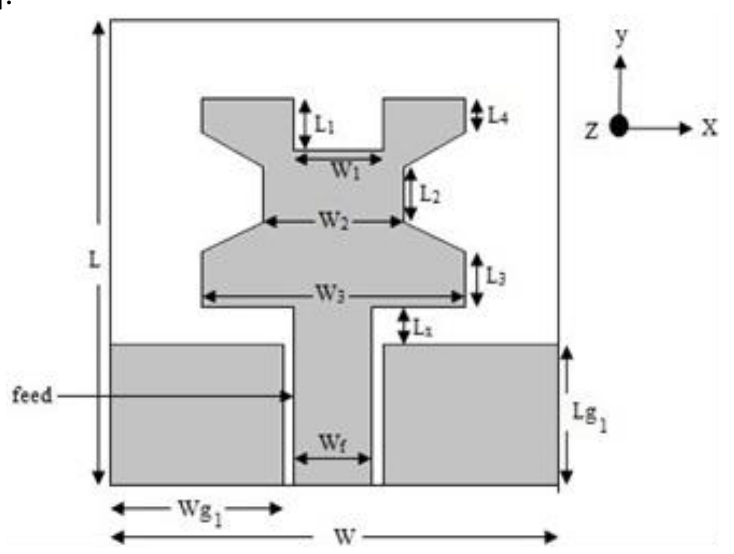

Figure 1. Structure of proposed CPW antenna
The geometrical dimensions are listed in Table 1.

Table 1. Geometrical dimensions of CPW antenna

\begin{tabular}{|c|c|}
\hline Dimension & Value \\
\hline Substrate $(\mathrm{L}, \mathrm{W}, \mathrm{h})$ & $20 \times 20 \times 1.5 \mathrm{~mm}^{3}$ \\
\hline Patch & $11 \times 8 \mathrm{~mm}^{2}$ \\
\hline Feedline Width $\left(\mathrm{W}_{\mathrm{f}}\right)$ & $3 \mathrm{~mm}$ \\
\hline Feedline length & $9 \mathrm{~mm}$ \\
\hline
\end{tabular}

The various dimensions of the patch are indicated in Table 2.

Table 2. Dimensions of radiating structure

\begin{tabular}{|c|c|}
\hline Parameter & Value $(\mathrm{mm})$ \\
\hline $\mathrm{Wg}_{1}$ & 8.1 \\
\hline $\mathrm{L}_{1}$ & 2 \\
\hline $\mathrm{W}_{2}$ & 11 \\
\hline $\mathrm{L}_{2}$ & 2 \\
\hline $\mathrm{L}_{3}$ & 2 \\
\hline $\mathrm{L}_{\mathrm{g}}$ & 7.8 \\
\hline $\mathrm{L}_{4}$ & 2 \\
\hline $\mathrm{W}_{3}$ & 7 \\
\hline
\end{tabular}

\section{Simulation and Results}

The designed CPW antenna was simulated using HFSS 11.0. The performance metrics such as return loss, VSWR, radiation pattern and input impedance were obtained from simulations. The critical parameters are chosen for parametric study. These parameters are a gap between ground planes and patch $\mathrm{Lx}$ and slot width $\mathrm{W}_{1}$. The other dimensions are kept unchanged as indicated in Table 2 while performing parametric studies. Figs. 2 - 3 demonstrate the simulation results of the return loss at different values of these parameters.

Fig. 2 shows the impact of slot length $\mathrm{W}_{1}$ on return loss. There is a change in resonating frequency and bandwidth with a change in the slot length. This parameter affects the return loss characteristics near the low and middle frequency. The lowest value of return loss is obtained while keeping $\mathrm{W}_{1}=3 \mathrm{~mm}$.

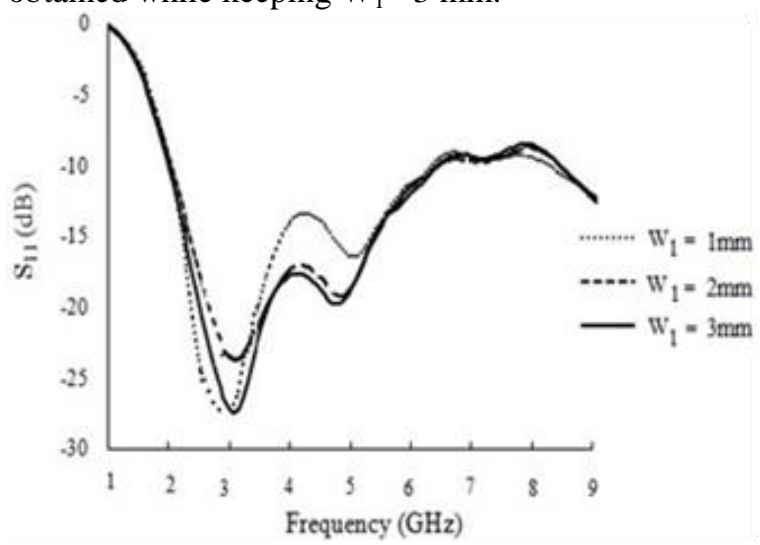

Figure 2. Impact of slot length $\mathrm{W}_{1}$ on return loss $\mathrm{S}_{11}$ 
From Fig. 3, it can be analyzed that as Lx increases from $1 \mathrm{~mm}$ to $1.4 \mathrm{~mm}$, the corresponding return loss changes for a whole band. So, to have proper coupling from feed to patch, this parameter has to be optimized. Three significant bands can be observed by keeping $\mathrm{Lx}=$ $1.4 \mathrm{~mm}$.

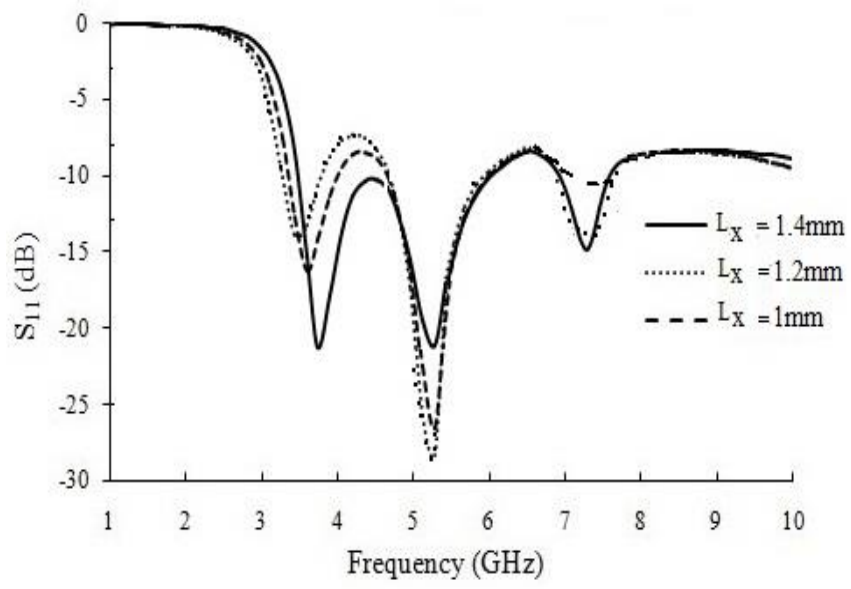

Figure 3. Impact of ground plane length $L x$ on return loss

From the parametric study, optimized values of parameters were obtained. The obtained optimized values are mentioned in Table 3.

Table 3. Dimensions of optimized parameters

\begin{tabular}{|c|c|}
\hline Dimension & Value $(\mathrm{mm})$ \\
\hline $\mathrm{W}_{1}$ & 3 \\
\hline $\mathrm{Lx}$ & 1.4 \\
\hline
\end{tabular}

Fig. 4 illustrates the simulated return loss curve over the entire frequency range. This antenna produces a dualband response. The lower band is centered at $3.6 \mathrm{GHz}$ with a bandwidth of $400 \mathrm{MHz}$ and the upper band is from $5.7 \mathrm{GHz}$ to $8 \mathrm{GHz}$. The values of $\mathrm{S}_{11}$ are $-20.7 \mathrm{~dB}$ at 3.6 $\mathrm{GHz}$ and $-28 \mathrm{~dB}$ at $5.8 \mathrm{GHz}$.

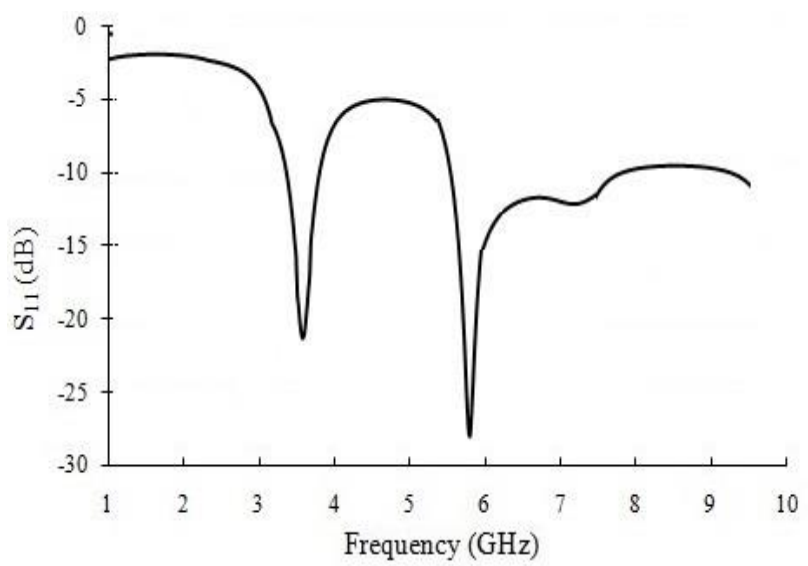

Figure 4. Simulated return loss versus frequency curve of design CPW antenna for optimized parameters
The simulated current density distribution in Fig. 5 shows that at $3.6 \mathrm{GHz}$ current is mainly concentrated near the feed and side portion of ground plane, whereas at $5.8 \mathrm{GHz}$ it spreads uniformly over the patch.

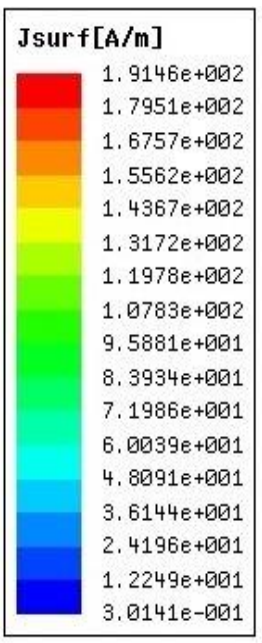

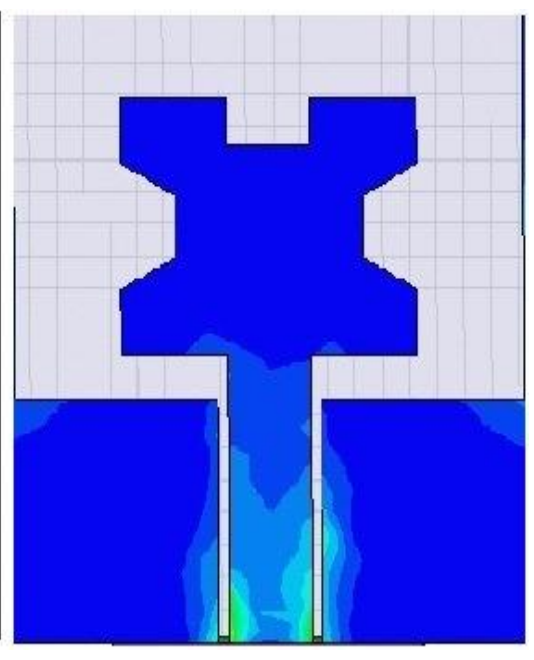

(a)

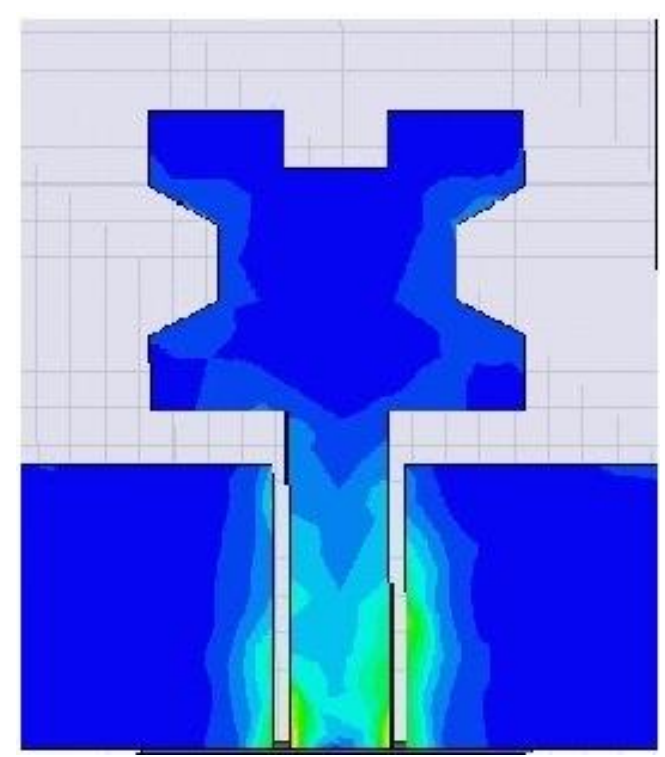

(b)

Figure 5. Simulated current density distribution at (a) $3.6 \mathrm{GHz}$ and (b) $5.8 \mathrm{GHz}$

Radiation patterns at $3.1 \mathrm{GHz}$ and $5.8 \mathrm{GHz}$ are plotted for two different values of $\phi$ as shown in Figure 6 (a) \& (b). The obtained, radiation patterns are omnidirectional, which are suitable for mobile communication. 


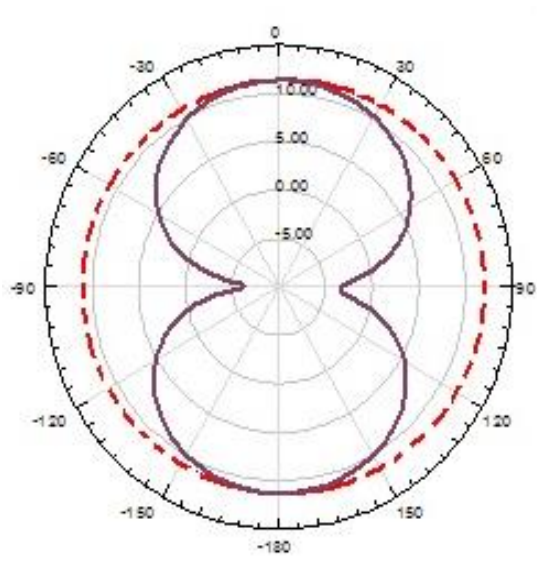

(a)

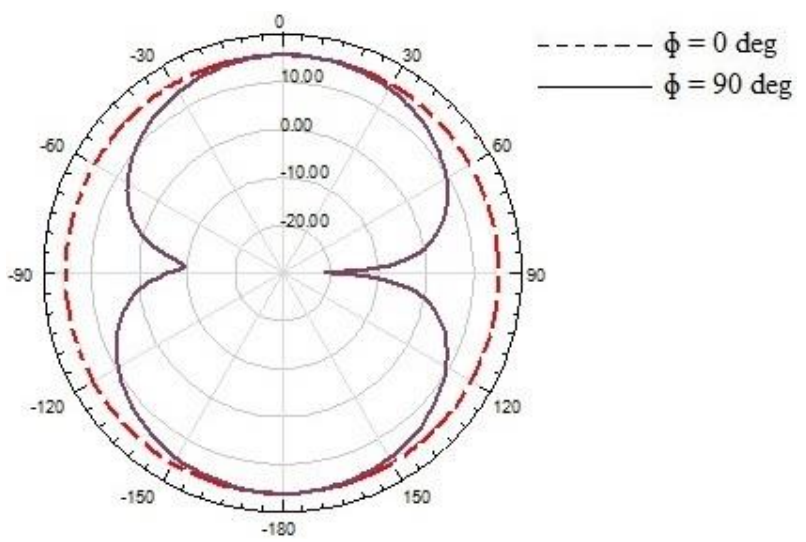

(b)

Figure 6. Radiation pattern plots of designed CPW antenna at (a) $3.1 \mathrm{GHz}$ and (b) $5.8 \mathrm{GHz}$

\section{Fabrication \& Testing}

The designed antenna is developed on an FR4 material as shown in Fig. 7 using photolithographic technique.

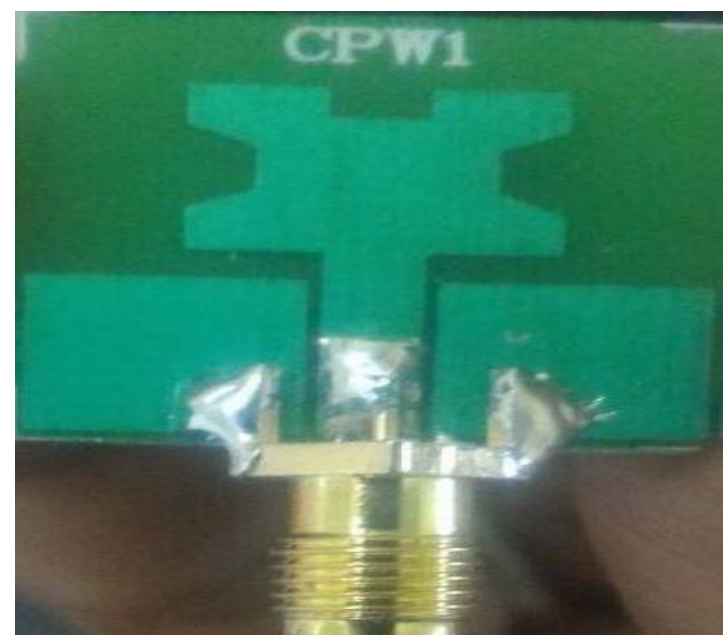

Figure 7. A photograph of fabricated CPW antenna
The testing of the fabricated antenna is performed using Anritsu MS46322A Vector Network Analyzer.

According to Fig. 8, the fabricated antenna was found to resonate at three different frequencies. The $1^{\text {st }}$ band resonates at $2.1 \mathrm{GHz}$ with a bandwidth of around 200 $\mathrm{MHz}$. The $2^{\text {nd }}$ band is at $3.7 \mathrm{GHz}$ with a minimum return loss of $-32 \mathrm{~dB}$ and $350 \mathrm{MHz}$ bandwidth. The $3^{\text {rd }}$ band is at $6.9 \mathrm{GHz}$ with a bandwidth of $1.1 \mathrm{GHz}$. The antenna response makes it suitable for various present generation wireless applications such as WLAN, RFID etc.

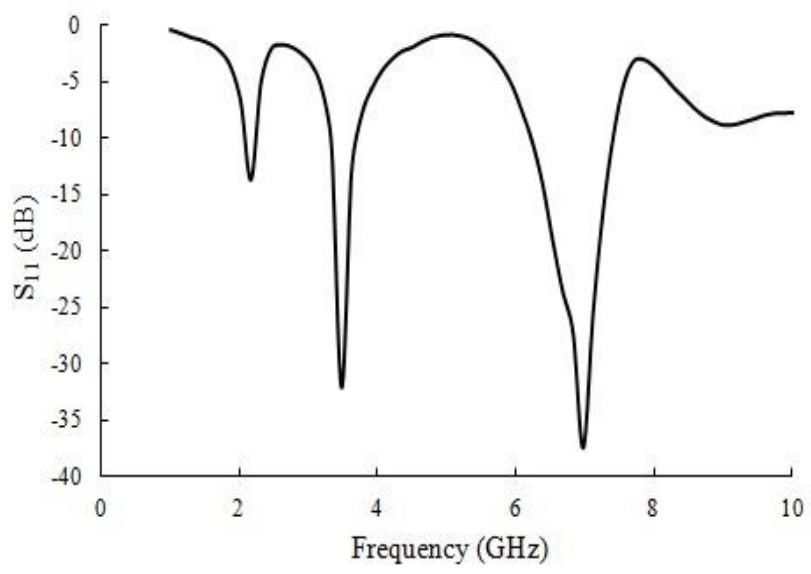

Figure 8. Measured return loss versus frequency curve of fabricated CPW antenna

All the obtained bands are suitable for different present generation mobile applications. The discrepancy between the simulated and measured results could be attributed to the fabrication inaccuracies and effect of improper soldering of SMA connector.

Fig. 9 gives the VSWR variation for the entire operating range. It can be seen that for three different bands VSWR values are less than 2 , which are desirable.

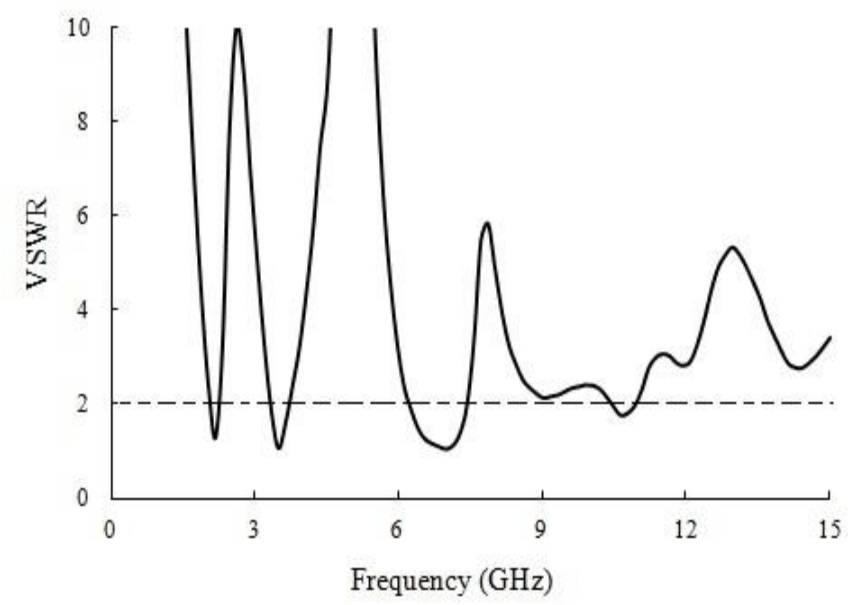

Figure 9. VSWR versus frequency plot of CPW antenna 
According to the measured impedance curve shown in Fig. 10, the fabricated antenna shows impedance matching close to $50 \mathrm{ohms}$ at point M1 $(5.06 \mathrm{GHz})$.

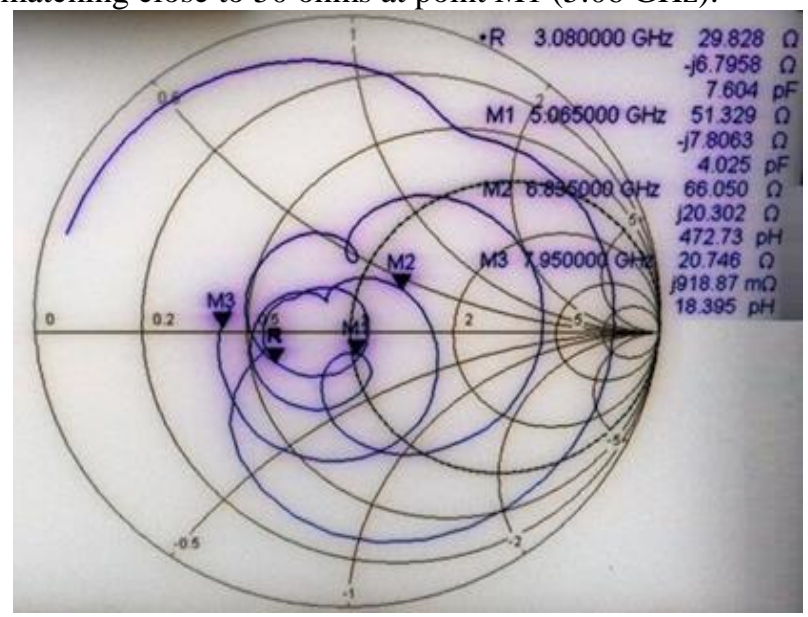

Figure 10. Measured Impedance curve of fabricated CPW antenna

\section{Conclusion and Future Scope}

In the present work, an ultra-wideband patch antenna with CPW feed is designed and analyzed. The simulated results display that the proposed antenna gives a dual-band response with a bandwidth of $2.3 \mathrm{GHz}$ for one of the band. The proposed antenna shows good properties such as dual band response at $3.1 \mathrm{GHz}$ and $5.8 \mathrm{GHz}$, omnidirectional radiation pattern, wide bandwidth and compact size etc. These properties make the designed antenna suitable for various wireless communication systems.

\section{References}

[1] FC Commission. (2002). Revision of part 15 of the commission's rules regarding ultra-wideband transmission systems. First report and order, 02-48.

[2] William, J. and Nakkeeran, R. (2010). A compact CPW-fed UWB slot antenna with cross tuning stub. Progress In Electromagnetics Research, (13): 159-170.

[3] Amar Touhami, N., Yahyaoui, Y., Zakriti, A., Bargach, K., Boussouis, M., Lamsalli, M. and Tribak, A. (2014). A compact CPW-fed planar pentagon antenna for UWB applications. Progress In Electromagnetics Research, (46): 153-161.

[4] Gautam, A. K., Yadav, S. and Kanaujia, B. K. (2013). A CPW-fed compact UWB microstrip antenna. IEEE Antennas and Wireless propagation letters, 12: 151-154.

[5] Liu, H., Zhu, S., Wen, P., Xiao, X., Che, W., \& Guan, X. (2014). Flexible CPW-fed fishtail-shaped antenna for dualband applications. IEEE antennas and wireless propagation letters, 13: 770-773.

[6] He, X., Shen, D., Zhou, Q., Zhang, X., Zeng, J. and Lv, Y. (2015). A novel CPW-fed compact UWB microstrip antenna. In IEEE International Symposium on Antennas and Propagation \& USNC/URSI National Radio Science Meeting: pp. 1972-1973.
[7] Sawant, K. K. andKumar, C. S. (2015). CPW fed hexagonal micro strip fractal antenna for UWB wireless communications. AEU-International Journal of Electronics and Communications, 69(1): 31-38.

[8] Si, L. M., Sun, H. J., Yuan, Y., \& Lv, X. (2009). CPW-fed compact planar UWB antenna with circular disc and spiral split ring resonators. In PIERS Proceedings: pp. 502-505.

[9] Unnikrishnan, D., Kaddour, D., Tedjini, S., Bihar, E., \& Saadaoui, M. (2015). CPW-fed inkjet printed UWB antenna on ABS-PC for integration in molded interconnect devices technology. IEEE Antennas and Wireless Propagation Letters, 14: 1125-1128.

[10] Peng, L., Wen, B. J., Li, X. F., Jiang, X., \& Li, S. M. (2016). CPW fed UWB antenna by EBGs with wide rectangular notched-band. IEEE Access, 4: 9545-9552.

[11] Alibakhshi-Kenari, M., Naser-Moghadasi, M., Sadeghzadeh, R. A., Virdee, B. S., \& Limiti, E. (2016). Bandwidth extension of planar antennas using embedded slits for reliable multiband $\mathrm{RF}$ communications. $A E U$ International Journal of Electronics and Communications, 70(7): 910-919.

[12] Sharma, M. and Goel, A. K. (2018) Reconfigurable Dual Notched Band UWB Antenna. IEEE International Conference on Computing, Power and Communication Technologies (GUCON): 843-847. 